(2) Now apply internal pressure. This distends the tube, stretching the roof and floor. The inner wall is compressed with a longitudinal thrust, and the outer wall stretched with a longitudinal tension, but the change in the diameter $\mathrm{AB}$, or in the diameter $A^{\prime} \mathrm{R}^{\prime}$, will be practically unobservable.

The action on the original gauge and its enclosed fluid of the added part and its fluid, consists now of the forces indicated in the figure, and which amount, as I have in my previous letter pointed out, to a couple (counter-clock-wise in the present tigure).

(3) Now replace the ends at $\mathrm{AA}^{\prime}$ and $\mathrm{BB}^{\prime}$ (this makes no difference in the equilibrium), and holding $\mathrm{AA}^{\prime}$ fixed, remove the added part.

The gauge will now uncurl, for we are removing the counterclock-wise couple necessary to maintain equilibrium. Or, to put it in other words, the outer wall $\mathrm{ACB}$, on being released from the tension at $\mathrm{B}$ shortens, while the inner wall being released from the pressure at $B^{\prime}$ becames longer, thus causing the gauge to uncurl.

As to Gauss's purely geometrical theorem, I fail to see how it is to be of any use in the analysis of the forces, which I take to be the real problem. All that Gauss says to us by his theorem is, "Pure bending in your gauge means uncurling ; if, therefore, you can prove that the forces are such as to produce pure bending, you prove that they produce uncurling." But this is exactly what we cannot prove. Indeed, it is admitted that the bending is not pure. And it is, I think, of no use to urge, with Lord Rayleigh, that the bending is nearly pure on account of the comparative inextensibility of the material, for that argument would apply equally to the gauge with both ends fixed, or to a complete annulus which obviously cannot uncurl. In fact, if we could go back to Gauss and ask, "Is it any use showing that the bending is "nearly pure'?" he would ask us what we meant by "nearly," and before we could answer that we should have to analyze the whole action. It is for these reasons that I consider the reference to Gauss's theorem not only unfruitful but misleading.

If we apply the method I have suggested to a tube of elliptical or other than rectangular section, we see that unless longitudinal stresses such as I have dwelt upon would exist in the walls were the annulus completed, the distended gauge will not uncurl on the removal of the added part, and the only reason for considering the curvature of either wall in a plane perpendicular to the circular axis, is that such curvature may, on account of the properties of the material by which it is able to distribute stress in different directions, lead to additions to or subtractions from (and conceivably therefore reversals of) the longitudinal thrust or tension that would exist in a tube of rectangular section. But this is obviously a question of the structure of the material and not of pure geometry.

R.N.E. College, Devonport, May I4.

\section{A Subject-Index and the Royal Society.}

THE following brief account of an offer I have made to the Royal Society will, I think, prove of interest to the readers of NATURE, and especially to those correspondents who have emphasized the importance of a subject-index for the progress of science in all its branches.

Upon the conclusion, last autumn, of five years' work, during which my "Epitome of the Synthetic Philosophy" was compiled, I commenced to look for some literary work which would be of undoubted practical service to science, and which would if possible aid its further development. The articles and numerous letters then appearing in your columns urging the importance of a subject classification of the memoirs arranged under the authors" names in the "Royal Society Catalogue of Scientific Papers," led me to discuss the advisability of my undertaking such a proceeding with several friends upon whose judgment I could rely with the result that, one and all agreeing upon the value of such a work, I wrote to Sir G. G. Stokes, P.R.S. (to whom I was directed), offering to compile the manuscript of the greater portion of such a work upon the condition that, as soon as the manuscript was completed and approved by the Council of the Royal Society, the Society should guarantee all expenses of print and publication. I was forced to say "the greater portion" of such a work (" 70 to 80 per cent."), for examination of a large number of titles had shown me that a certain percentage of them could only be correctly indexed by specialists in their own departments, a fact which is emphasized when we call to mind that a title may be in any one of eight European languages.

NO. IO75, VOL. 42$]$
After several interviews with Sir G. G. Stokes, and a somewhat protracted correspondence, I agreed to arrange a sample index of some 2000 entries upon a plan suggested by him, and warmly approved by that eminent bibliographer Dr. Garnett, of the British Museum, the plan being to take the leading word or words in the title of each paper, with a reference to the volume, page, author's name, and number of the paper, in the Royal Society's Catalogue, for subsequent arrangement in alphabetical order, by which means the subject-key would occupy but a quarter of the bulk of the Catalogue as now published. It would extend-that is, approximately - to three quartos of the size of the present volumes, in similar type, \&c.

In the early part of May this plan was discussed by the Catalogue Committee of the Royal Society, when the following resolution was passed:- "That the offer of Mr. Collins be declined, and that the President be requested to convey to $\mathrm{Mr}$. Collins the best thanks of the Committee for the trouble which he has taken."

The foregoing account will be sufficient to show that, contrary to an opinion expressed more than once in these pages, something more is needed than an offer to compile the subjectindex. Were the manuscript now completed, and approved by the Royal Society, there would still be wanting a sum sufficient to bring it before the public.

In conclusion, I should like to express my warm thanks to Sir George Stokes for the kind and courteous way in which he has assisted me in my endeavour to develop what I am still convinced would be of immense service to science in all parts of the civilized world; and not only to science, but to many industries besides. For would not the cbemical manufacturer and the dyer profit by a complete list of all the papers that had been written on the coal-tar colours; the agriculturist, by knowing the researches which had been undertaken to ascertain the nutritive powers of the bones and phosphates, and the fattening properties of the various cakes and foods; the engineer, the analyses of iron and steel with their accompanying properties; the physician, the physiological action of the various drugs; and the electrician, all the papers, for instance, which had been written upon that little understood subject, induced currents? Finally, how many millions might have been saved in the construction of harbours all over the British Empire had all the scattered information upon the flow of water in rivers and tidal estuaries been so gathered together as to make reference possible, not to say easy?

Churchfield, Edgbaston.

F. Howard COllins.

\section{Stream Lightning.}

IF a candle-flame is put between the poles of an electrical machine, while it is giving rough angular sparks, the discharge at once changes into a smooth single line of very easy curvature it suggests the difference between sinuous and stream lightning: it is not merely that the spark is as if shortened by the conducting flame ; the whole nature of the discharge is changed. If the flame is held two inches beneath the poles, the spark will go down to it.

Winchester College, May zo.

\section{Atmospheric Circulation.}

ON March 9 and 10, 1887, the barometer rose to $30^{\circ} 92$ inches over Iceland-a very exceptional height for that locality at that time of the year. The United States daily maps of the northern hemisphere show that a storm to the southward of this great anticyclone was carried westward a distance of over six hundred miles within twenty-four hours, in a manner similar to that in which West Indian hurricanes follow the course of the trade winds in August and September, although this storm was located in latitude $40^{\circ} \mathrm{N}$., or in the usual situation of the anti-trades. Other instances of a similar character have been noted, but this one was unusually well defined, and throws much light upon the laws governing the atmospheric circulation.

Lyons, N.Y., May 20.

M. A. VEEDER.

\section{Testing for Colour-Blindness.}

IN answer to Prof. Lodge's query (May 29, p. I00), why those concerned in testing for colour-vision do not avail themselves of instruments like Lord Rayleigh's, having tested some thousands in this city, I may state that experience has shown that they are 